\title{
Bite marks on the frill of a juvenile Centrosaurus from the Late Cretaceous Dinosaur Provincial Park Formation
}

\author{
David W E Hone ${ }^{\text {Corresp., }}{ }^{1}$, Darren H Tanke ${ }^{2}$, Caleb M Brown ${ }^{2}$ \\ ${ }^{1}$ School of Biological and Chemical Sciences, Queen Mary University of London, London, United Kingdom \\ 2 Royal Tyrrell Museum, Drumheller, Alberta, Canada \\ Corresponding Author: David W E Hone \\ Email address: dwe_hone@yahoo.com
}

Bite marks on bones can provide critical information about interactions between carnivores and animals they consumed (or attempted to) in the fossil record. Data from such interactions is somewhat sparse and is hampered by a lack of records in the scientific literature. Here we present a rare instance of feeding traces on the frill of a juvenile ceratopsian dinosaur from the late Campanian Dinosaur Park Formation of Alberta. It is difficult to determine the likely tracemaker(s) but the strongest candidate is a small-bodied theropod such as a dromaeosaur or juvenile tyrannosaur. This marks the first documented case of carnivore consumption of a juvenile ceratopsid, but may represent scavenging as opposed to predation. 
1 Bite marks on the frill of a juvenile Centrosaurus from the Late Cretaceous Dinosaur

2 Provincial Park Formation, Alberta, Canada

3

4 David W. E. Hone ${ }^{1}$

5 Darren H. Tanke ${ }^{2}$

6 Caleb M. Brown ${ }^{2}$

7

8 1. School of Biological and Chemical Sciences, Queen Mary, University of London,

$9 \quad$ London, UK

2. Royal Tyrrell Museum of Palaeontology, Drumheller, Alberta, Canada

11

12 Corresponding author: David Hone, d.hone@qmul.ac.uk 


\section{Abstract:}

15 Bite marks on bones can provide critical information about interactions between carnivores and animals they consumed (or attempted to) in the fossil record. Data from such interactions is somewhat sparse and is hampered by a lack of records in the scientific literature. Here we present a rare instance of feeding traces on the frill of a juvenile ceratopsian dinosaur from the late Campanian Dinosaur Park Formation of Alberta, Canada. It is difficult to determine the likely tracemaker(s) but the strongest candidate is a small-bodied theropod such as a dromaeosaur or juvenile tyrannosaur. This marks the first documented case of carnivore consumption of a juvenile ceratopsid, but may represent scavenging as opposed to feeding after 23 predation.

\section{Introduction:}

Bite marks on the bones of fossils can provide important information as to the palaeoecology of ancient ecosystems and as indicators of trophic interactions between animals. In the case of the non-avian dinosaurs (hereafter simply 'dinosaurs'), bite marks (that are healing, healed and peri- or post-mortem) can allow inferences about both inter- and intraspecific interactions in various clades. This includes inferences about cannibalism (Bell \& Currie, 2010; Longrich et al., 2010, Hone \& Tanke, 2015), scavenging (Hone \& Watabe, 2010), intraspecific combat (Tanke \& Currie, 1998), interspecific combat (Happ, 2008), prey preferences (Jacobsen, 1998), and attempted predation (De Palma et al., 2013). However, there are major problems with

34 the use of bite mark data which has limited its potential for interpreting dinosaur behaviour and 35 ecology. 
Although tooth-marks are not uncommon for dinosaurs, they are considerably more

37

common in tyrannosaur-dominated faunas (Fiorillo, 1991) and can be regularly seen in some

formations such as Dinosaur Park Formation (authors pers. obs.). Even so, relatively few marks

have been described in detail to date, which limits comparisons or large-scale assessments of patterns across multiple traces (though see e.g. Jacobsen, 1998).

Identification of both parties associated with bite marks (i.e. both the carnivore and the consumed sensu Hone \& Tanke, 2015) is often difficult, limiting the available information.

Bitten specimens are often fragmentary, and as bite marks are commonly found on isolated elements, these are often not diagnostic to genera or species. Similarly, bite marks are often difficult to attribute to tracemakers (e.g. see Hone \& Chure, 2018), although specimens that include shed teeth of a feeding carnivore (e.g. Currie \& Jacobsen, 1995; Maxwell \& Ostrom, 1995; Hone et al., 2010), or where there are single credible candidates for the tracemaker (e.g. Bell \& Currie, 2010; Longrich et al., 2010) are known, allowing for a confident referral. Finally, there are often difficulties in interpreting the actions of the tracemakers based on bite mark data (Chure, Fiorillo, \& Jacobsen, 2000; Robinson, Jasinski \& Sullivan, 2015). It is difficult to separate out scavenging events from those associated with late stage carcass consumption of a prey item without supporting taphonomic data (e.g. see Hone \& Watabe, 2010). Bites may have been made by multiple different tracemaker species, or at different times, and traces can potentially be altered through erosion or transport which further restricts interpretations.

6 Collectively then, this makes interpretations of bite trace data difficult, although it also means that every recorded bite event may be valuable as it is only through the collection and assessment of large datasets that patterns can be assessed. In this context, unusual or rare marks 
59

60

61

62

63

64

65

66

67

68

69

70

71

72

73

74

75

76

77

78

79

80

81

may be especially important for determining the range of possible interactions and events based on theropod bites.

Here we describe a number of small marks on a partial frill of a juvenile ceratopsian (referred to Centrosaurus apertus). Bite marks on ceratopsians are known (e.g., Erickson et al., 1996; Jacobsen, 1998; Happ, 2008, Fowler et al., 2006) but are restricted to larger bodied animals making this the first description of bites on such a young individual. Determining the tracemaker is not possible given the range of possible candidates but this may represent an example of a small-bodied carnivore (i.e., Dromaeosauridae, Troodontidae or juvenile Tyrannosauridae) feeding on the young of a much larger-bodied taxon.

\section{Materials and Methods:}

The present specimen (Royal Tyrrell Museum of Palaeontology specimen TMP 2014.012.0036) represents a fragment of the squamosal of a subadult centrosaurine ceratopsid (Fig 1), from the lower Dinosaur Park Formation (Campanian) of southern Alberta. It was found by DHT and collected under Park Research and Collection Permit (No. 14-095) from Alberta Tourism, Parks and Recreation, as well as a Permit to Excavate Palaeontological Resources (No. 14-018) from Alberta Culture and Tourism and the Royal Tyrrell Museum of Palaeontology, both issued to CMB, and is accessioned at the Royal Tyrrell Museum of Palaeontology, Drumheller.

The fossil was collected from the surface of a multi-taxic bonebed in the core area of Dinosaur Provincial Park (UTM, 12U: 464,462 E; 5,621,335 N, WGS 84). Stratigraphically, the specimen is from the lower Dinosaur Park Formation ( $\sim 5 \mathrm{~m}$ above the contact with the underlying Oldman Formation), and falls between the radiometrically dateable Jackson Coulee 
82 (min. 76.32 Ma) and Plateau (75.60 +/- $0.02 \mathrm{Ma}$ ) bentonites (Dave Eberth, pers. comm., 2017).

83 This confidently places the specimen within the Corythosaurus-Centrosaurus zone (Ryan et al.,

84 2012; Mallon et al., 2013), and as result, is here referred to Centrosaurus apertus as this is the

85 only centrosaurine ceratopsid species known to occur in this well sampled ( $>20$ diagnostic skulls,

86 and $\sim 20$ bonebeds) interval (Eberth and Getty, 2005; Brown, 2013).

$87 \quad$ Multiple systems have been used to describe and define bite marks, and other traces on

88 bones such as trampling, in both the palaeontological and anthropological literature (e.g.

89 Behrensmeyer, Gordon \& Yanagi, 1986; Hone \& Watabe, 2010). Here we follow the system of

90 Hone \& Watabe (2010) as this was created to refer to a series of theropod traces and has been

91 used by a number of different research groups to identify and classify bite marks on dinosaur,

92 and other Mesozoic reptile, bones.

93

94

95

96

97

98

99

100

101

102

103

104

\section{Description:}

Specimen TMP 2014.012.0036 is identified as a fragment of squamosal of a small centrosaurine ceratopsid dinosaur (Fig 1). The specimen is subtriangular in shape and approximately $8 \mathrm{~cm}$ per side and just over $1 \mathrm{~cm}$ thick. It represents the posterior corner of the lateral margin of the squamosal and is from a position just ventral to the suture with the parietal (Fig 2). It was broken in several places prior to fossilisation, but part of the original lateral margin remains intact and shows the scalloped edge of the frill.

Four independent lines of evidence suggest this element derived from a non-adult animal. Firstly, despite limited wear to the element, the majority of the surface is unweathered and shows the distinctly striated long grained bone texture of juvenile centrosaurine frill elements (Sampson, Ryan \& Tanke, 1997; Brown, Russell \& Ryan, 2009; Tumarkin-Deratzian, 2010). 
105 Secondly, the preserved lateral margin of the element is straight, and bears no evidence of the 106 imbrication of the loci undulations that develop during ontogeny (Sampson, Ryan \& Tanke, 107 1997). Thirdly, the partially preserved epiossification locus is without fused epiossification seen 108 in many (but not ubiquitously preserved) adults (Sampson, Ryan \& Tanke, 1997; Horner and 109 Goodwin 2008). Finally, the cross-sectional thickness of the element $(<10 \mathrm{~mm})$ and the overall 110 small size of the one preserved episquamosal loci (see Supplementary Data) indicate a small 111 absolute size of the entire squamosal. Taken together, this suggests the animal was below 112 osteologically adult maturity (cf Hone, Farke, \& Wedel, 2016), and falls into the juvenile age 113 class established by Sampson, Ryan \& Tanke (1997). The absolute size of the animal in life is difficult to estimate from the limited remains,

115 but comparison with a sample of 24 more complete juvenile/subadult squamosals derived from 116 monodominant centrosaurine bonebeds (Centrosaurus apertus, Coronosaurus brinkmani,

117 Pachyrhinosaurus lakustai), suggest the complete squamosal would have had a marginal length 118 of approximately $204 \mathrm{~mm}$, and a maximum length of approximately $293 \mathrm{~mm}$. For comparison, 119 osteologically mature $C$. apertus specimens have squamosals ranging in marginal length of 258$120373 \mathrm{~mm}($ mean $=322 \mathrm{~mm})$, total length of 288-481 $\mathrm{mm}($ mean $=401 \mathrm{~mm})$, for skulls ranging in 121 basal skull length of $660-868 \mathrm{~mm}($ mean $=779 \mathrm{~mm})$. The suggests the tooth-marked squamosal 122 represents an individual with linear skull measures around two-thirds to three-quarters (64-73\%) 123 the size of the average ontogenetically adult Centrosaurus apertus skull, and approximately one124 half (48-61\%) the size of the largest Centrosaurus apertus skull. Although this may not sound 125 small in comparison, due to the cubic scaling of mass relative linear measures, this equates to an 126 animal less than one-third $(\sim 29 \%)$, and less than one-seventh $(\sim 13 \%)$, the mass of the average 
127 and largest adult, respectively. This also likely represents an underestimate due to potential

128 negative allometry of the skull relative to the body.

129 The specimen as preserved has a light coloured and dark coloured side, presumably the

130 former being somewhat bleached by exposure to the sun and rain prior to discovery. The texture

131 on the surface (fine striations) is similar on both sides, suggesting this is a genuine feature and

132 not the result of erosion or exposure. It is not possible to confidently determine which surface is

133 internal and which is external, and as a result, the lighter coloured side is referred to as 'Side A',

134 with the darker side as 'Side B'. A number of features and marks are seen on the specimen that

135 are described below and are numbered as in Figure 3. Part of the lateral margin of the element is

136 broken (which is common in isolated parts of ceratopsian frills), but one aspect of this retains a

137 natural edge.

138

139 Side A (Figure 3A):

140

141 1. A groove on the surface of the bone, which has a counterpart (i) on side B.

142 2. A thin score that cuts through the cortex. It is long and especially narrow being $18 \mathrm{~mm}$ by

$1431 \mathrm{~mm}$ at the widest, and mostly circa $0.5 \mathrm{~mm}$ wide.

144 3. A small oval mark $(6.5$ by $3 \mathrm{~mm})$ near the margin of the bone. This is uneven and slightly ' $\mathrm{Z}$ ' 145 shaped.

146 4-6. A series of marks that resemble cracks. There is some matrix infill of the marks so the 147 margins are not entirely clear. Number 5 is rather irregular and 4 in particular matches other very 148 small cracks in general form. 
149 7. A slight mark on the edge of the bone, near the broken margin. It is small and oval in shape

150 and parallel to the frill margin. The mark is $5 \mathrm{~mm}$ long by $1.5 \mathrm{~mm}$ wide.

151 8. A small but deep mark on the broken margin that is associated with some damage to the frill

152 margin. The mark is $5 \mathrm{~mm}$ long, $1.7 \mathrm{~mm}$ deep, and as it is at the broken margin, the width cannot

153 be determined.

154

155 Side B (Figure 3B):

156 i. A long groove that has some slight damage to one edge of it. This runs parallel to mark 1 on 157 side A.

158 ii. Two shallow scores, one is broad and the second very thin that departs the former at a shallow 159 angle. The thin side branch does not cut across the fibers of the bone cleanly. The larger trace is $16018 \mathrm{~mm}$ long and up to $1.25 \mathrm{~mm}$ wide.

161 iii. A short and proportionally deep penetration of the bone, which appears to be broken at the 162 margins. The mark is $11.5 \mathrm{~mm}$ long, up to $4 \mathrm{~mm}$ wide, and $3 \mathrm{~mm}$ deep (it is deeper proximally 163 and becomes more shallow towards the margin). There is a little wear internally as it is smooth in 164 places including the margins.

165 iv. A comparatively broad mark that is up to $11.75 \mathrm{~mm}$ long, $2.25 \mathrm{~mm}$ wide, and is 166 approximately $1 \mathrm{~mm}$ deep. The trace is slightly curved along its length.

$167 \mathrm{v}$. This is a small and narrow score mark that is $17 \mathrm{~mm}$ long and $1 \mathrm{~mm}$ wide, and closely 168 associated with mark iv. The depth cannot be measured accurately, but is estimated to be under $1690.5 \mathrm{~mm}$. This is subparallel to ii and iii.

170 vi. A triangular mark that lies at the margin of the piece. The mark is $7 \mathrm{~mm}$ long, as preserved, 171 and $1.8 \mathrm{~mm}$ deep. This lies close to mark iii. 


\section{Discussion}

The specimen here shows a mixture of mark types which are considered to be the result

175

176

177

178

of a combination of effects. The element was found as an isolated piece and not from one of the ceratopsian bonebeds that are common in Dinosaur Provincial Park. Given the isolated nature of the fragment (removed from the rest of the skeleton), and the abraded nature of the breaks, it is likely to have undergone some transport and erosion given that it was not associated with any other parts of a young Centrosaurus. This also means that its exact taphonomic history is unknown and thus caution is required when interpreting the limited data.

Breaks to ceratopsian frills are common and thus there is little to take from the separation of the element from the rest of the skull, or the broken margin. Although these are major breaks to this small bone, there is some wear at the edges (suggesting transport and perhaps chemical wear) and the breaks are not clearly associated with possible bites. On side A in particular there are a series of cracks (4-6) on the surface that align with the natural striations on the bone (see Figs 1 and 3) and the larger manifestations of the long-grained bone texture associated with immature frills (Sampson, Ryan \& Tanke, 1997; Brown, Russell \& Ryan, 2009; TumarkinDeratzian, 2010). Although they are subparallel to each other which is a very common feature of theropod bite marks (e.g. Currie \& Jacobsen, 1995; Chure, Fiorillo, \& Jacobsen, 2000; Hone \& Watabe, 2010), they also align very well with the general orientation of fibers and smaller cracks on the opposite (B) surface, and are here considered to be aspects of bone growth not alteration. Mark 7 is an odd shape that does not resemble a bite mark and as it is close to the break of the frill margin, it is suggested that this may be part of an impact that lead to this damage, possibly through trampling (known in some cases to break bones - Olsen \& Shipman, 1988) or transport. 
195

196

197

198

199

200

201

202

203

204

205

206

207

Although different in form, the marks at point ii are likely also cracks resulting from the same stress as these also primarily align with the natural form of the bone and the cracks seen on the surface.

Marks 1 and i are considered the remains of vascular grooves. They are both broad and shallow and very smooth making them quite unlike typical bite marks. Mark 3 is less clearly defined than others on the bone and the shallow and rounded nature of this make it likely to be part of another vascular groove as with marks 1 and $i$.

Marks ii, iv and v are difficult to interpret and may be considered bite marks, but this is uncertain. Mark ii is slightly tear-drop shaped and does not follow the grain of the bone as with the above marks so it is not part of a crack associated with long grain bone texture. It is however relatively shallow and smooth unlike typical bite marks, although perhaps altered through erosion. This may therefore be the result of a small impact during transport. Similarly, marks iv and $\mathrm{v}$ are subparallel which is a common feature of bite marks however they are also rather irregular in shape and do not track each other closely as would be expected for adjacent teeth in a jaw and mark iv has a somewhat sinusoidal pattern. These marks are also smooth and worn, and broad and shallow which is unlike most bite marks, though their identity is unclear. They may be more vascular pathways, or eroded damage, or perhaps both.

Marks 8 and vi are relatively deep into the cortex and come at the broken margins of the piece and thus could potentially represent bites that penetrate the cortex and thus may have in part led to the breaking off of the piece. These marks are therefore tentatively assigned as bite marks, but may well be the result of damage from transport and erosion.

This leaves two traces on the specimen that are confidently interpreted as bite marks, trace 2 on the side A and iii on side B. Mark 2 is a narrow trace which does correspond in 
218 general form to other bite traces seen on bones from the Dinosaur Park Formation (though these

219 are typically considerably larger - DWEH pers obs). This is a long and thin 'diamond' shape

220 tapering to points at each end, although there is also some damage to the margins of this where

221 the bone splintered as the mark was inflicted or perhaps through later erosion. It corresponds to a

222 drag mark (sensu Hone \& Watabe, 2010) where the tooth does not break through the cortex of

223 the bone. In longitudinal section (Fig 4) this is deepest in the middle and more shallow at each

224 end and is approximately v-shaped in cross section.

225 Mark iii is close in morphology to a bite and drag (sensu Hone \& Watabe, 2010) where

226 the tooth penetrates deep into the bone and then is pulled back. This corresponded with the

227 orientation of the bite which is from proximal to distal on the frill being deeper more proximally,

228 and is more shallow towards the frill margin. In cross section this is U-shaped (Fig 4) and in

229 longitudinal section is seen to be relatively short and deep with the deepest part towards the

230 centre of the element.

231

232 Tracemaker identity:

233 The marks here do not correspond well to those of non-dinosaurian carnivores known

234 from the Dinosaur Park Formation and thus can be ruled out. There are lizards, crocodiles,

235 champsosaurs, and mammals known which could potentially have bitten on dinosaur bone.

236 However, extant crocodiles tend to splinter bones when biting and also leave sub-circular

237 punctures not seen here (e.g. see Naju \& Blumenschine, 2006; Drumheller and Brochu, 2014;

238 Botfalvai, Prondvai \& Ösi, 2014) and large lizards tend to leave curved traces because the head

239 sweeps in an arc during feeding (D’Amore \& Blumenschine, 2009). There are no bite marks

240 currently assigned to champsosaurs, but they might be expected to feed in similar ways to either 
241 or even both of these techniques (based on their gross anatomy and phylogenetic ancestry) which

242 would not match the traces seen here, and they are widely regarded as piscivorous (Russell,

243 1956). The marks also do not correspond with inferred traces from mammals known from the

244 underlying Oldman Formation of Alberta which appear as repeated pairs of short and wide

245 notches in the bone (Longrich and Ryan, 2010).

246 With these ruled out, the most likely candidates are therefore the non-avian theropods.

247 Three clades of toothed, carnivorous, forms are known from these beds: tyrannosaurs,

248 dromaeosaurs, troodontids as well as the genus Richardoestesia which is of uncertain affinities

249 (Currie, 2005). Although at adult size, the tyrannosaurs are very large, bite marks from smaller

250 individuals remain a possibility.

251 Mark 2 is a good match for the very thin and blade-like teeth of dromaeosaurs and

252 troodontids which would leave proportionally thin traces with a narrow v-shaped cross section.

253 Indeed, these marks are a good match in general form for bite marks left by dromaeosaurs in the

254 formation which can be positively identified because of a shed tooth (Currie \& Jacobsen, 1995).

255 Long and straight bites from tyrannosaurs are typically left as a result of scrape feeding where

256 the premaxillary teeth are drawn across the cortex (Hone \& Watabe, 2010) and usually leave

257 multiple subparallel traces that are broad because of the D-shaped nature of the teeth and these

258 are therefore rather unlike mark 2.

259 The morphology of trace iii however, is very different from that of 2 , being much more

260 broad and deep and with a U-shaped cross section implying a more blunt tooth made the mark.

261 As noted above, this shape may have been exaggerated by later erosion, but this would still be

262 different to the relatively thin and well-defined trace 2. Although slightly elongate, this is closest

263 to a puncture mark (sensu Hone \& Watabe, 2010) and would be a good match for a tyrannosaur 
264 tooth (premaxillary or maxillary / dentary). Similarly, the traces 3,8 , and vi, if they are bites,

265 would more closely match tyrannosaurs given their general broad and deep nature. At least some

266 deep puncture wounds that may be attributed to larger dromaeosaurs are known (Gignac et al.,

267 2010) and such traces do seem to be relatively rare. Even when a dromaeosaur tooth was

268 punctured into a pterosaur bone with enough force to remove the tooth this was not driven deep

269 into the bone and there were no other associated punctures (Currie and Jacobsen, 1995).

270 The mixture of trace morphology, coupled with the likely erosion of at least some marks

271 makes the identity of the tracemaker difficult to determine. It may have been a dromaeosaurid

272 (cf. Gignac et al., 2010) or young tyrannosaur (cf. Longrich et al., 2010), or possibly both.

273 Although we are not aware of any bite marks on dinosaur fossils that can be attributed to

274 multiple species this is something which might be predicted - modern carcasses may be fed on

275 by multiple species through kleptoparasitism (Höner et al., 2002) or simply feeding on carrion

276 after the original predator has moved on (Lanszki et al., 2015).

277

Interpretation:

279 In all cases $(2,3,8$, iii, vi) the traces are well separated from one another and not a series

280

281

282

283

284

285

286 of punctures or sub-parallel marks that are typical of theropod bite traces. Marks may be

inconsistent in this regard thanks to the different lengths of theropod teeth in the jaws and possible absences etc. such that a bite may only result in one or two teeth engaging with the bone. In the case of traces 8 and vi which abut the broken margins, these may represent a bite on the now missing part of the frill where only a single tooth contacted the squamosal. Single traces made by theropod teeth are certainly known in a number of cases (e.g. some traces in Erickson \& Olson, 1996; Tanke \& Currie, 1998; Gignac et al., 2010; Hone \& Tanke, 2015;) and so despite 
287 the unusual arrangement of these traces, we are confident that several of these do represent bite 288 marks.

Superposition of the two sides of the squamosal piece (Fig 5) shows that marks 3, iii, and 290 vi are close to one another and 3 and iii even partially overlap. However, iii lies at a very

291

292

293 different angle to the other marks and this is hard to reconcile as being associated with them. In contrast, traces 3 and vi are in a similar location and have a similar orientation suggesting they may be the result of a single bite engaging both sides of the frill.

No major muscle groups or abundant soft tissues such as fat deposits are likely associated with the squamosal of ceratopsian dinosaurs. As such, feeding on this part of the skull was likely a result of late stage carcass consumption (see Hone \& Rauhut, 2010 and references therein) whereby feeding only occurred as a result of the more nutritious aspects of the carcass having been exploited (Fig 6). The small size of the animal may imply that the carcass was exploited quickly - indeed, large theropods like tyrannosaurs were apparently capable of processing and consuming most or all of a juvenile dinosaur (Chin et al., 1998). As a result, although juvenile dinosaurs were likely common components of dinosaurian faunas, they were at least in part rare in the fossil record as a result of destruction by theropod feeding (Hone \& Rauhut, 2010). As a result, despite the apparent preferences for feeding on juvenile dinosaurs, most described bite marks are on the bones of adults which may have resisted being consumed and destroyed (even by large tyrannosaurs) and thus feeding traces on a juvenile dinosaur remain unusual. Perhaps the size and shape of ceratopsian crania, even in juveniles, made them difficult to process or required an excess of handling effort for a relatively low reward.

\section{Conclusions:}


carnivores and consumed species. Such traces attributed to tyrannosaurs are more common than

312 for other theropod dinosaurs but even so few have been described in detail despite the

313 information that may be available to help interpret their ecology and behaviour. This first

314 evidence of likely scavenging on a non-adult animal adds to the known diversity of animals

315 apparently fed on by Late Cretaceous tyrannosaurs.

316

317 Acknowledgements:

318 We thank Marie-Hélène Trudel-Aubry for her artwork as used in figure 6. We thank Brandon

319 Strilisky for his help as collections manager and David Eberth for preliminary updated

320 radiometric dates for the specimen. We thank You Hai-Lu, Domenic D’Amore and Stephanie

321 Drumheller-Horton for their comments which improved the manuscript and Mathew Wedel for 322 his handling of this as editor.

\section{References:}

325 Behrensmeyer AK, Gordon KD, Yanagi GT. 1986. Trampling as a cause of bone surface damage 326 and pseudo-cutmarks. Nature 319:768-771.

327 Bell PR, Currie PJ. 2010. A tyrannosaur jaw bitten by a confamilial: scavenging or fatal 328 agonism? Lethaia 43:278-281.

329 Botfalvai G, Prondvai E, Ösi A. 2014. Inferred bite marks on a Late Cretaceous (Santonian) 330 bothremydid turtle and a hylaeochampsid crocodilian from Hungary. Cretaceous Research, $331 \quad 50: 304-317$. 
332 Brown CM, Russell AP, Ryan MJ. 2009. Pattern and transition of surficial bone texture of the

333 centrosaurine frill and their ontogenetic and taxonomic implications. Journal of Vertebrate 334 Paleontology 29:132-141.

335 Brown CM. 2013. Advances in quantitative methods in dinosaur palaeobiology: a case study in 336 horned dinosaur evolution. $\mathrm{PhD}$ thesis, University of Toronto.

337

338

Chin K, Tokaryk TT, Erickson GM, Calk LC. 1998. A king-sized theropod coprolite. Nature 393:680-682.

Chure DJ, Fiorillo AR, Jacobsen R. 2000. Prey bone utilization by predatory dinosaurs in the Late Jurassic of North America, with com ments on prey bone use by dinosaurs throughout the Mesozoic. Gaia 15:227-232.

Currie PJ. 2005. Theropods, including birds. In: Currie PJ, Koppelhus EB, eds. Dinosaur Provincial Park. Bloomington: Indiana University Press, 367-397.

Currie PJ, Jacobsen AR. 1995. An azhdarchid pterosaur eaten by a velociraptorine theropod. Canadian Journal of Earth Sciences 32:922-925.

D'Amore DC, Blumensehine RJ. 2009. Komodo monitor (Varanus komodoensis) feeding behavior and dental function reflected through tooth marks on bone surfaces, and the application to ziphodont paleobiology. Paleobiology 35:525-552.

DePalma RA, Burnham DA, Martin LD, Rothschild BM, Larson PL. 2013. Physical evidence of predatory behavior in Tyrannosaurus rex. Proceedings of the National Academy of Sciences $110: 12560-12564$.

Drumheller SK, Brochu CA. 2014. A diagnosis of Alligator mississippiensis bite marks with comparisons to existing crocodylian datasets. Ichnos 21:131-146. 
354 Eberth DA, Getty MA. 2005. Ceratopsian bonebeds: occurrence, origins, and significance. In:

355 Currie PJ, Koppelhus EB eds. Dinosaur Provincial Park: a spectacular ancient ecosystem

356 revealed. Bloomington: Indiana University Press, 501-536.

357 Erickson GM, van Kirk SD, Su J, Levenston ME, Caler WE, Carter DR. 1996. Bite-force

358 estimation for Tyrannosaurus rex from bone-marks. Nature 382:706-708.

359 Erickson GM, Olson KH. 1996. Bite marks attributable to Tyrannosaurus rex: preliminary

360 description and implications. Journal of Vertebrate Paleontology 16:175-178.

361 Fiorillo AR. 1991. Prey bone utilisation by predatory dinosaurs. Palaeogeography,

362 Palaeoclimatology, Palaeoecology 88:157-166.

363 Fowler DW, Sullivan RM. 2006.A ceratopsid pelvis with toothmarks from the Upper Cretaceous

364 Kirtland Formation, New Mexico: evidence of Late Campanian tyrannosaurid feeding behaviour. New Mexico Museum of Natural History and Science Bulletin 35:127-130.

Gignac PM, Makovicky PJ, Erickson GM, Walsh RP, 2010. A description of Deinonychus antirrhopus bite marks and estimates of bite force using tooth indentation simulations. Journal of Vertebrate Paleontology 30:1169-1177.

369

370

371

372

373

374

375

Gilmore CW. 1914. A new ceratopsian dinosaur from the Upper Cretaceous of Montana, with note on Hypacrosaurus. Smilthsonian Miscellaneous Collections 63:1-10.

Happ J. 2008. An analysis of predator-prey behavior in a head-to-head encounter between Tyrannosaurus rex and Triceratops. In: Larson P, Carpenter K. eds. Tyrannosaurus rex the Tyrant King. Bloomington: Indiana University Press, 355-370

Hone DWE, Chure DJ. 2018. Difficulties in assigning trace makers from theropodan bite marks: an example from a young diplodocoid sauropod. Lethaia, 51:456-466 
376 Hone DWE, Rauhut OWM. 2010. Feeding behaviour and bone utilisation by theropod dinosaurs. $377 \quad$ Lethaia 43:232-244.

378 Hone DWE, Tanke DH. 2015. Pre-and postmortem tyrannosaurid bite marks on the remains of

379 Daspletosaurus (Tyrannosaurinae: Theropoda) from Dinosaur Provincial Park, Alberta, $380 \quad$ Canada. PeerJ 3:p.e885.

381 Hone DWE, Watabe M. 2010. New information on the feeding behaviour of tyrannosaurs. Acta 382 Palaeontologica Polonica 55:627-634.

383 Hone DWE, Choiniere J, Sullivan C, Xu X, Pittman M, Tan Q. 2010. New evidence for a tropic 384 relationship between the dinosaurs Velociraptor and Protoceratops. Palaeogeography, 385 Palaeoclimatology, Palaeoecology 291:488-492.

386 Hone DWE, Farke AA, Wedel MJ. 2016. Ontogeny and the fossil record: what if anything is an 387 adult dinosaur? Biology Letters 12:20150947.

Höner OP, Wachter B, East ML, Hofer H. 2002. The response of spotted hyaenas to long-term changes in prey populations: functional response and interspecific kleptoparasitism. Journal of Animal Ecology 71:236-246.

Horner JR, Goodwin MB. 2008. Ontogeny of cranial epi-ossifications in Triceratops. Journal of Vertebrate Paleontology 28:134-144.

Jacobsen AR. 1998. Feeding behavior of carnivorous dinosaurs as determined by tooth marks on dinosaur bones. Historical Biology 13:17-26.

Lanszki J, Kurys A, Heltai M, Csányi S, Ács K. 2015. Diet composition of the golden jackal in an area of intensive big game management. Annales Zoologici Fennici 52:243-255.

Longrich NR, Ryan MJ. 2010. Mammalian tooth marks on the bones of dinosaurs and other Late Cretaceous vertebrates. Palaeontology 53:703-709. 
399 Longrich NR, Horner JR, Erickson GM, Currie PJ. 2010. Cannibalism in Tyrannosaurus rex. $400 \quad$ PloS one 5:p.e13419.

401 Mallon JC, Evans DC, Ryan MJ, Anderson JS. 2013. Megaherbivorous dinosaur turnover in the 402 Dinosaur Park Formation (upper Campanian) of Alberta, Canada. Palaeogeography, 403 Palaeoclimatology, Palaeoecology 350:124-138.

404 Maxwell WD, Ostrom JH. 1995. Taphonomy and paleobiological implications of 405 Tenontosaurus-Deinonychus associations. Journal of Vertebrate Paleontology 15:707-712.

406 Njau JK, Blumenschine RJ. 2006: A diagnosis of crocodile feeding traces on larger mammal 407 bone, with fossil examples from the Plio-Pleistocene Olduvai Basin, Tanzania. Journal of $408 \quad$ Human Evolution 50:142-162.

409 Olsen SL, Shipman P. 1988. Surface modification on bone: trampling versus butchery. Journal $410 \quad$ of archaeological science, 15:535-553.

411 Robinson RF, Jasinski SE, Sullivan RM. 2015. Theropod bite marks on dinosaur bones:

412 indications of a scavenger, predator or both?; and their taphonomic implications. New Mexico Museum of Natural History and Science Bulletin 68:275-282.

Russell LS. 1956. The Cretaceous Reptiles Champsosaurus Natator Parks (Vol. 145). Canada. Department of Northern Affairs and National Resources.

Ryan MJ, Evans DC, Currie PJ, Brown CM, Brinkman D. 2012. New leptoceratopsids from the Upper Cretaceous of Alberta, Canada. Cretaceous Research 35:69-80.

418 Sampson SD, Ryan MJ, Tanke DH. 1997. Craniofacial ontogeny in centrosaurine dinosaurs 419 (Ornithischia: Ceratopsidae): taxonomic and behavioral implications. Zoological Journal of 420 the Linnean Society 121:293-337. 
421 Tanke DH, Currie P. 1998. Head-biting behavior in theropod dinosaurs: paleopathological 422 evidence. Gaia 15:167-184.

423 Tumarkin-Deratzian AR. 2010. Histological evaluation of ontogenetic bone surface texture

424

425

426

427

428

429

430

431

432

433

434

435

436

437

438

439

440

441

442 changes in the frill of Centrosaurus apertus. In: Ryan MJ, Chinnery-Allgeier BJ, Eberth

DA, eds. New Perspectives on Horned Dinosaurs, the Royal Tyrrell Museum Ceratopsian

Symposium. Bloomington: Indiana University Press, 251-263.

Fig 1. Photographs of TMP 2014.012.0036 showing side A and side B, identification of dorsal and ventral surfaces unclear. Thick outline (see fig 3) indicates preserved lateral margin. All other edges are broken bone surface. Scale bar is $50 \mathrm{~mm}$ long. Image credit: David Hone.

Fig 2. Reconstructed skull of a juvenile Centrosaurus apertus of approximately similar ontogenetic status to that of TMP 2014.012.0036 (A) in right lateral view, next to that of an adult (B). The two skulls are to scale with one another. The squamosal is highlighted in medium grey and the approximate outline of the specimen preserved here is in dark grey. Reconstruction of the juvenile skull based largely on USNM 7951 (Gilmore, 1914), with additions from TMP 1982.016.0011 and 1996.175.0064, adult based on YPM 2015. Scale bare is $200 \mathrm{~mm}$ long. Image credit: Caleb Brown. 
443 Fig 3. Interpretative drawing of TMP 2014.012.0036 showing side A and side B. Numbers relate

444 to various areas of interest as described in the text. Pale grey areas mark areas of wear to the bone, dark grey areas represent major features, and black areas are those that penetrate deep into the cortex. The thicker lines on the margins represent the natural margin of the element (see also figure 2). Scale bar is $50 \mathrm{~mm}$ long. Image credit: David Hone.

Fig 4. Interpretative drawings of cross-sections of the traces 2 and iii from TMP 2014.012.0036 based on silicone peels. Dark grey indicates the bone and pale grey the approximate extent of the missing bone. Scale bar is $1 \mathrm{~cm}$ with $1 \mathrm{~mm}$ divisions. Veritical and horizontal relief is

Fig 5. Interpretative drawing of TMP2014.012.0036 flipped such that the bite marks from the to the same scale. Image Credit: Caleb Brown.

459

Fig 6. Although the identity of the tracemaker of the marks on the Centrosaurus frill fragment is 461 uncertain, here we present a speculative reconstruction of scavenging by a juvenile

463 
Figure 1

Photographs of TMP 2014.012.0036 showing side A and side B.

Scale bar is $50 \mathrm{~mm}$ long. Image credit: David Hone.
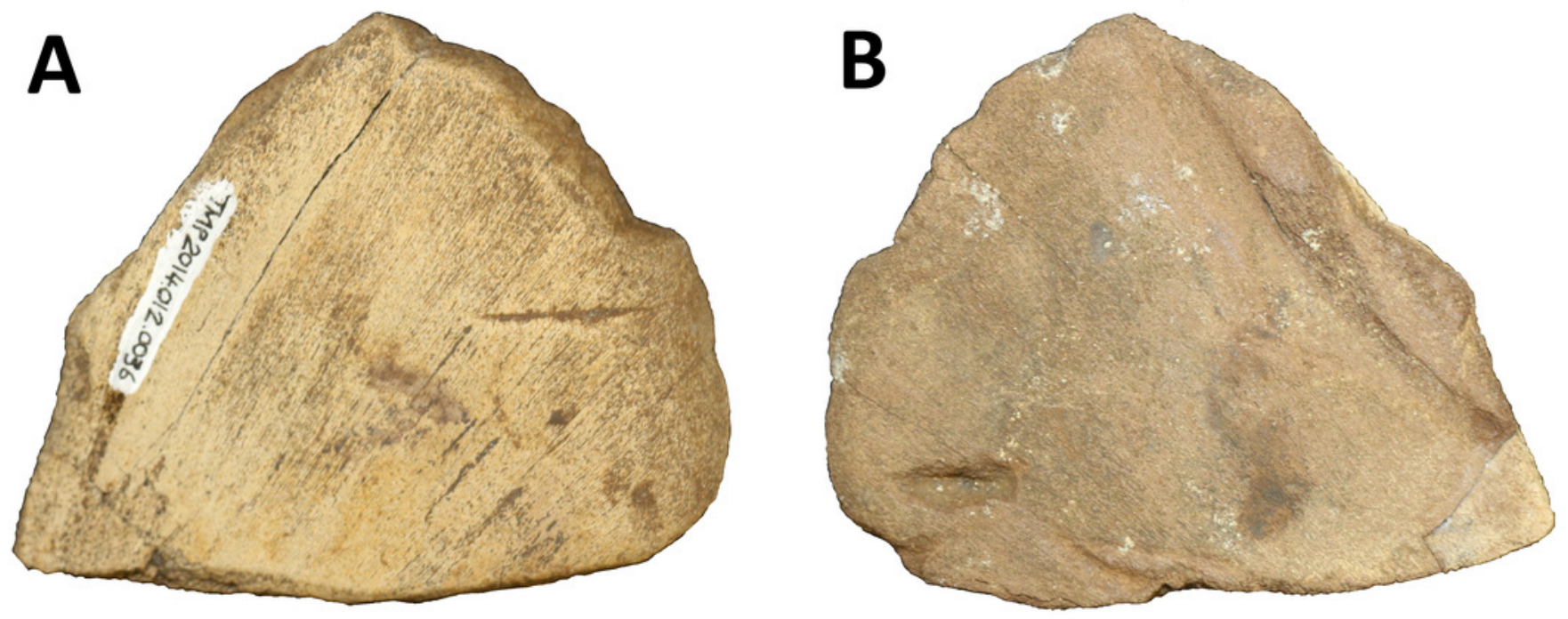


\section{Figure 2}

Reconstructed skull of a juvenile Centrosaurus apertus.

Reconstructed skull of a juvenile Centrosaurus apertus of approximately similar ontogenetic status to that of TMP 2014.012.0036 (A) in right lateral view, next to that of an adult (B). The two skulls are to scale with one another. The squamosal is highlighted in medium grey and the approximate outline of the specimen preserved here is in dark grey. Reconstruction of the juvenile skull based largely on USNM 7951 (Gilmore, 1914), with additions from TMP 1982.016.0011 and 1996.175.0064, adult based on YPM 2015. Image credit: Caleb Brown. 


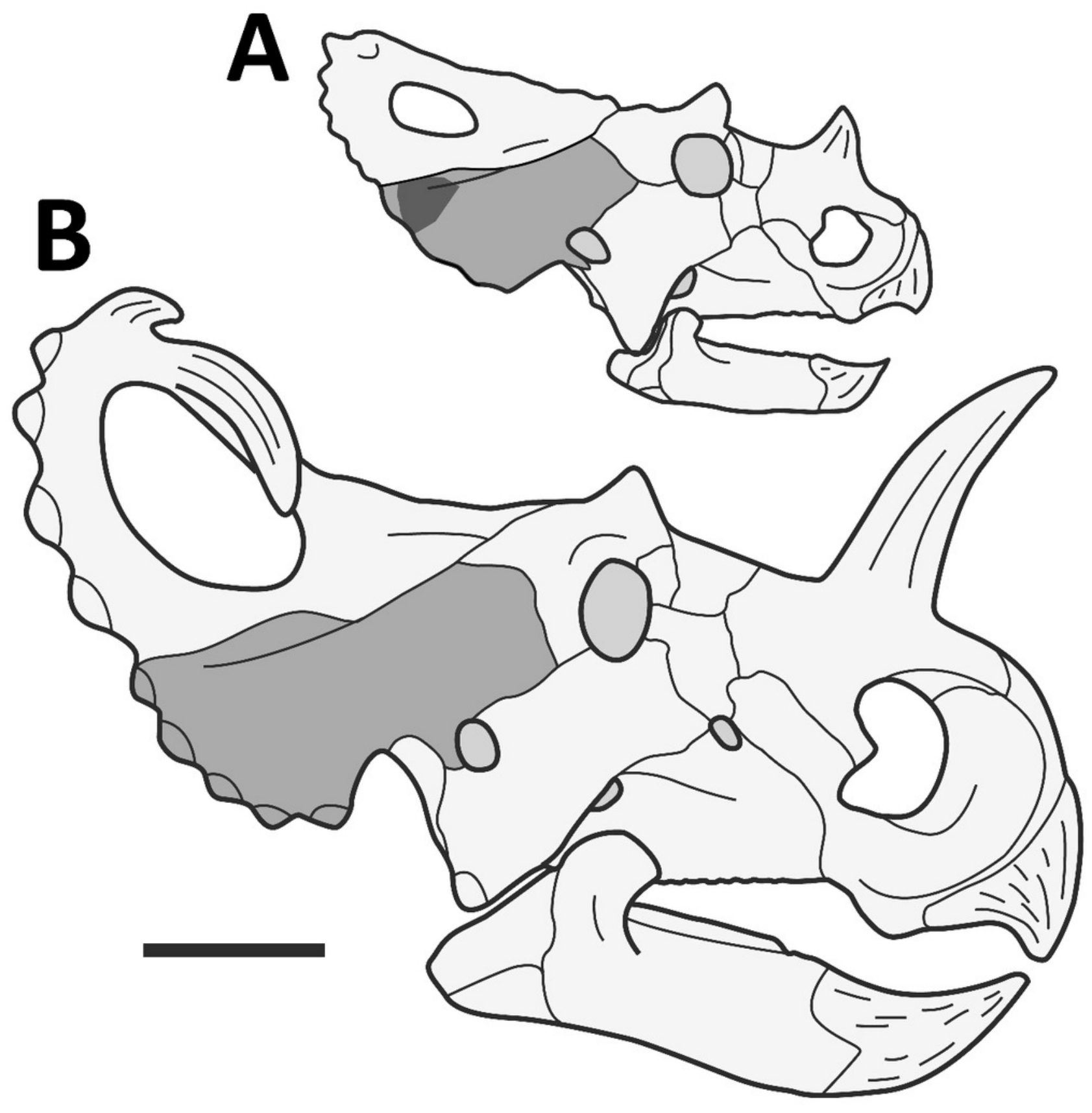


Figure 3

Interpretative drawing of TMP 2014.012.0036 showing side A and side B.

Numbers relate to various areas of interest as described in the text. Pale grey areas mark areas of wear to the bone, dark grey areas represent major features, and black areas are those that penetrate deep into the cortex. The thicker lines on the margins represent the natural margin of the element (see also figure 2). Scale bar is $50 \mathrm{~mm}$ long. Image credit: David Hone.

A

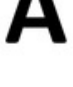

A

8

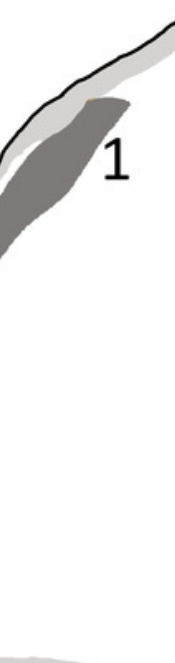

1
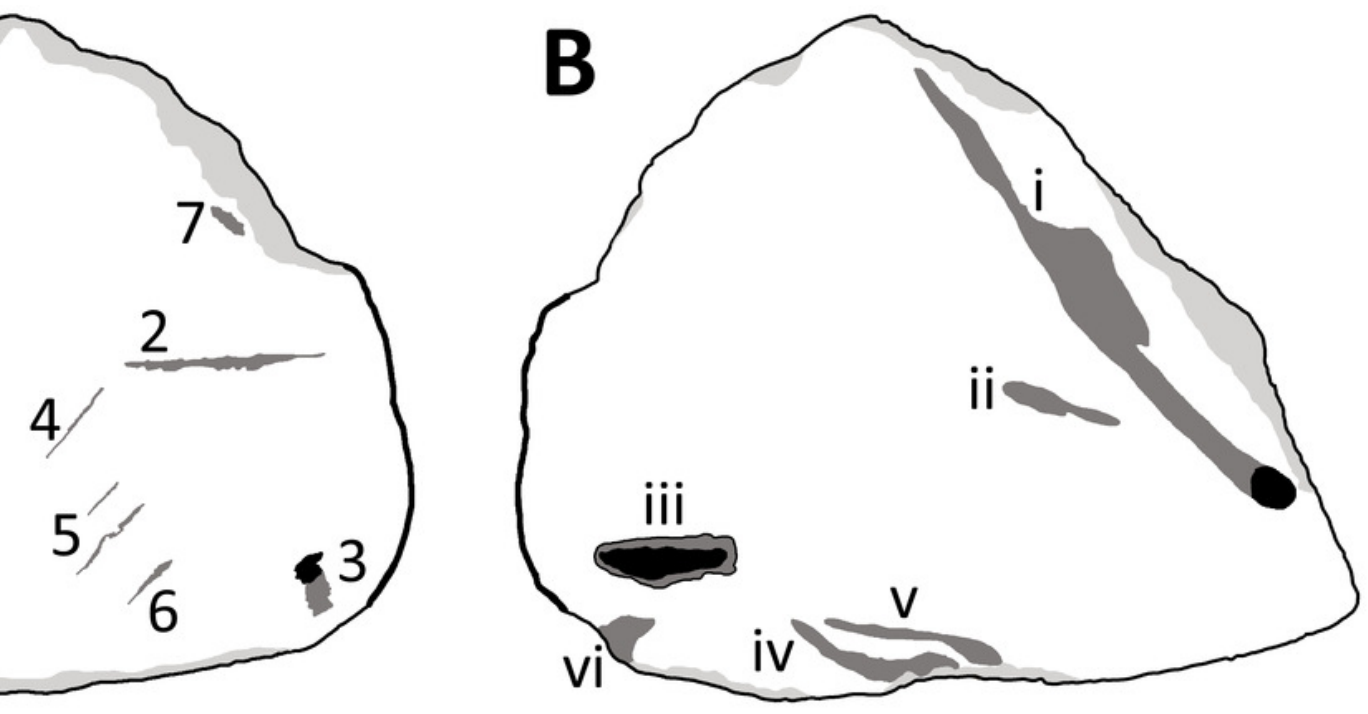
Figure 4

Interpretative drawings of cross-sections of the traces 2 and iii from TMP 2014.012.0036 based on latex peels.

Dark grey indicates the bone and pale grey the extent of the latex infill. Scale bar is $1 \mathrm{~cm}$ with $1 \mathrm{~mm}$ divisions. Image credit: Caleb Brown.

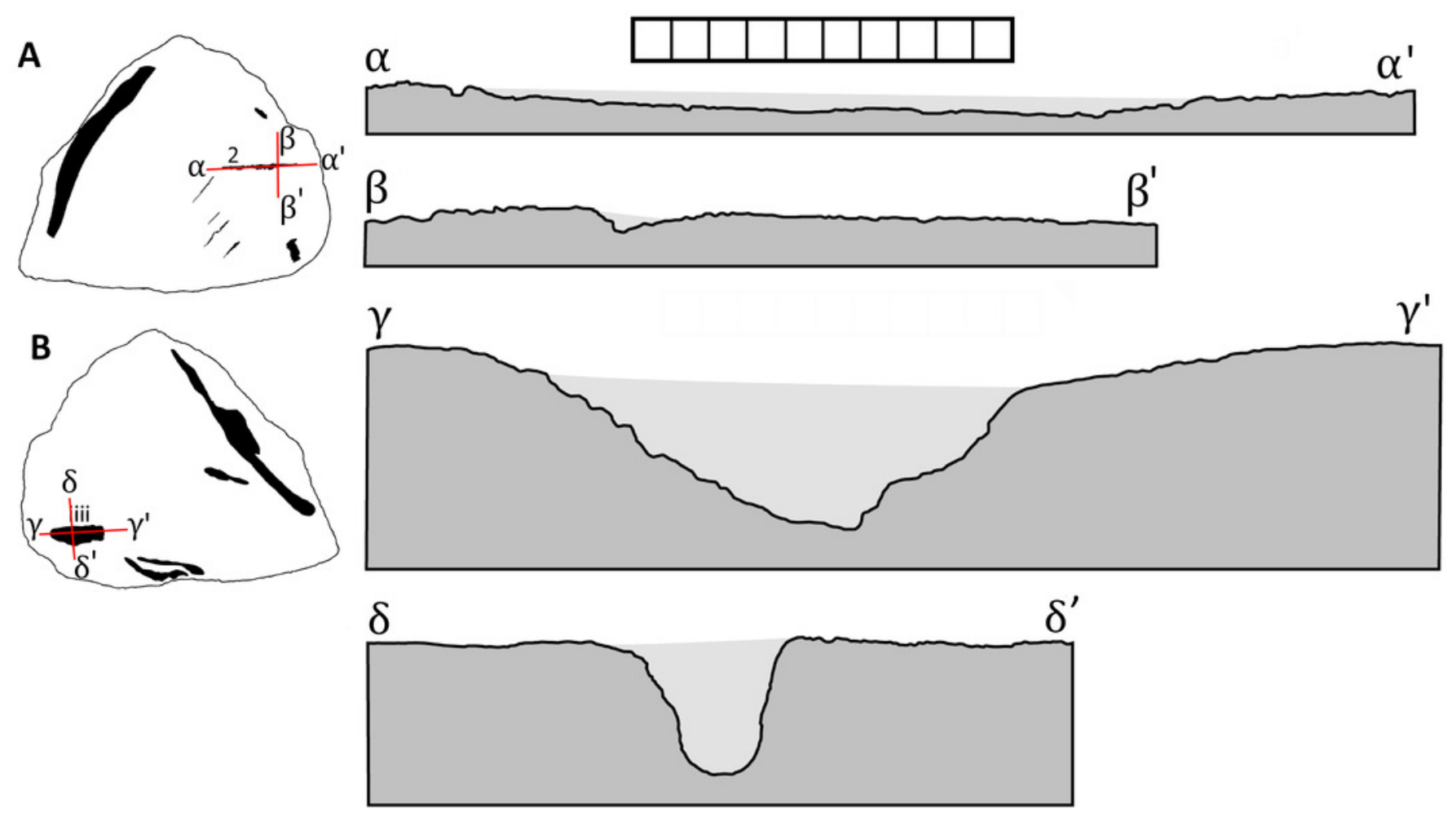


Figure 5

Interpretative drawing of TMP2014.012.0036 flipped such that the bite marks from the dorsal and ventral sides both appear

Dark grey areas represent major features, and black areas are those that penetrate deep into the cortex. The thicker line on the margins represent the natural margin of the element (see also figure 2). Scale bar is $50 \mathrm{~mm}$ long. Photo credit: Caleb Brown.

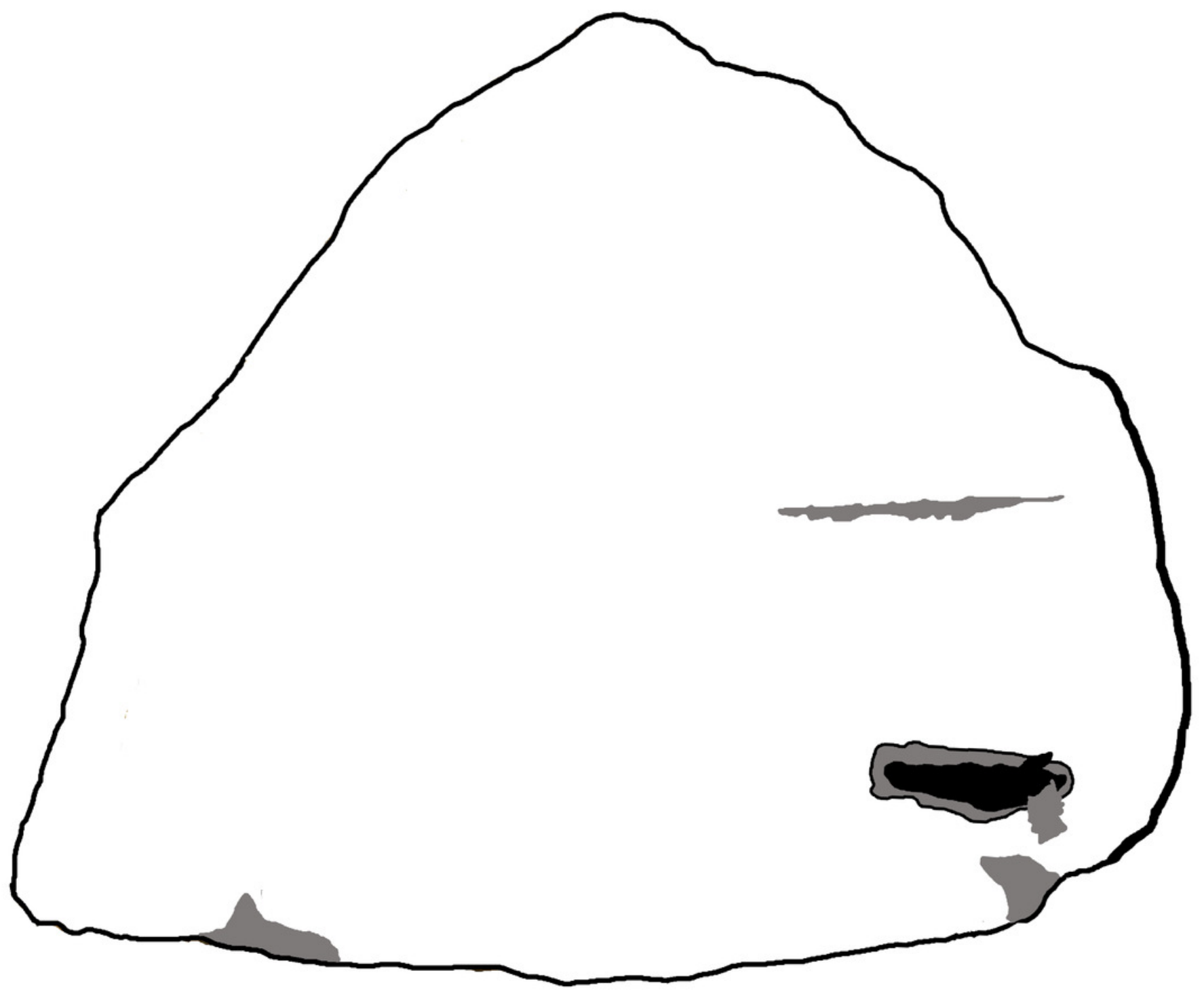


Figure 6

Speculative reconstruction of scavenging by a juvenile Gorgosaurus on the specimen Although the identity of the tracemaker of the marks on the Centrosaurus frill fragment is uncertain, here we present a speculative reconstruction of scavenging by a juvenile Gorgosaurus. Artwork by Marie-Hélène Trudel-Aubry and used with their permission.

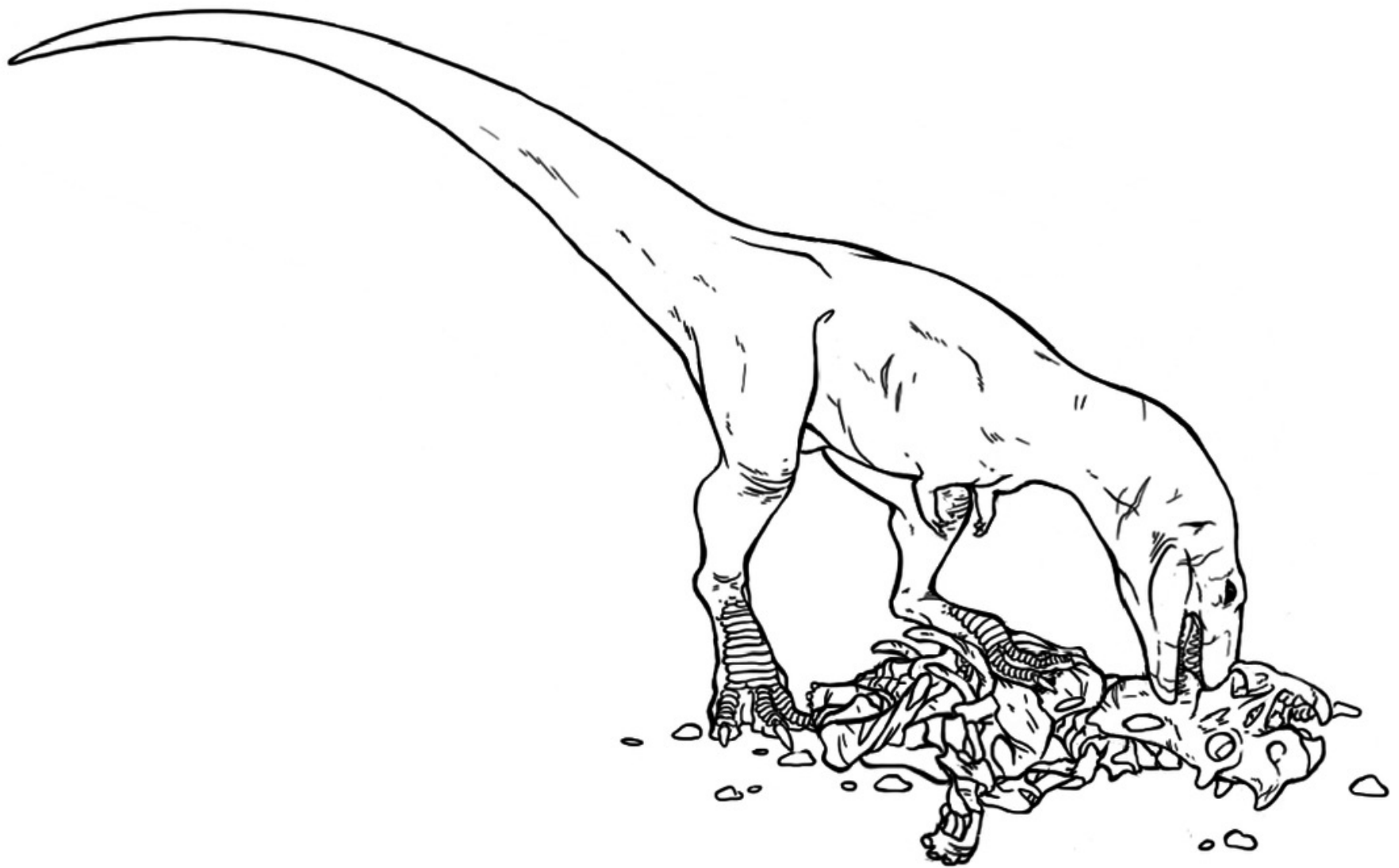

